\title{
Hip1r is expressed in gastric parietal cells and is required for tubulovesicle formation and cell survival in mice
}

\author{
Renu N. Jain, ${ }^{1}$ Asma A. Al-Menhali, ${ }^{1}$ Theresa M. Keeley, ${ }^{1}$ Jianhua Ren, ${ }^{1}$ \\ Mohammed El-Zaatari, ${ }^{2}$ Xunsheng Chen, ${ }^{3}$ Juanita L. Merchant,, ${ }^{1,2}$ \\ Theodora S. Ross, ${ }^{2}$ Catherine S. Chew,$^{3}$ and Linda C. Samuelson ${ }^{1}$
}

\begin{abstract}
1Department of Molecular and Integrative Physiology and 'Department of Internal Medicine, University of Michigan, Ann Arbor, Michigan, USA. 3Institute of Molecular Medicine and Genetics, Medical College of Georgia, Augusta, Georgia, USA.
\end{abstract}

\begin{abstract}
Huntingtin interacting protein 1 related (Hip1r) is an F-actin- and clathrin-binding protein involved in vesicular trafficking. In this study, we demonstrate that Hip1r is abundantly expressed in the gastric parietal cell, predominantly localizing with F-actin to canalicular membranes. Hip1r may provide a critical function in vivo, as demonstrated by extensive changes to parietal cells and the gastric epithelium in Hip1r-deficient mice. Electron microscopy revealed abnormal apical canalicular membranes and loss of tubulovesicles in mutant parietal cells, suggesting that Hip1r is necessary for the normal trafficking of these secretory membranes. Accordingly, acid secretory dynamics were altered in mutant parietal cells, with enhanced activation and acid trapping, as measured in isolated gastric glands. At the whole-organ level, gastric acidity was reduced in Hip1r-deficient mice, and the gastric mucosa was grossly transformed, with fewer parietal cells due to enhanced apoptotic cell death and glandular hypertrophy associated with cellular transformation. Hip1rdeficient mice had increased expression of the gastric growth factor gastrin, and mice mutant for both gastrin and Hip1r exhibited normalization of both proliferation and gland height. Taken together, these studies demonstrate that Hip1r plays a significant role in gastric physiology, mucosal architecture, and secretory membrane dynamics in parietal cells.
\end{abstract}

\section{Introduction}

Huntingtin interacting protein 1 (Hip1) and Hip1 related (Hip1r) comprise a family of proteins that are thought to function broadly in membrane trafficking. These proteins are related to the yeast protein Sla2p, which has previously been shown to be required for several membrane-associated functions, including polarization of the cortical actin cytoskeleton, cell growth, and endocytosis $(1,2)$. The mammalian proteins Hip1 and Hip1r also appear to play central roles in intracellular membrane movement. They bind clathrin light chain via a coiled-coil domain and have been shown to promote clathrin cage assembly in vitro $(3,4)$. Accordingly, these proteins colocalize with clathrin coat components, including coated endocytotic pits at the cell surface and clathrin-coated vesicles emerging from the trans-Golgi network (5). Both proteins also contain a talin domain that binds F-actin, thus potentially linking clathrin to the actin cytoskeleton. Finally, the N-terminus contains an AP180 $\mathrm{N}$-terminal homology (ANTH) domain that binds inositol lipids, which may play a role in bridging cell membranes with cytoskeletal and clathrin coat components $(6,7)$. The protein domain structure suggests that Hip1 and Hip1r play important roles in clathrin-coated vesicle formation or membrane trafficking.

Functional studies in cultured mammalian cells have supported a role for Hip1r in clathrin-mediated vesicle formation.

Nonstandard abbreviations used: AP, aminopyrine; GSII, Griffonia simplicifolia lectin II; Hip1, Huntingtin interacting protein 1; Hip1r, Hip1 related; Lasp-1, LIM and SH3 protein 1; qRT-PCR, quantitative RT-PCR; SPEM, spasmolytic polypeptide-expressing metaplasia.

Conflict of interest: The authors have declared that no conflict of interest exists. Citation for this article: J. Clin. Invest. 118:2459-2470 (2008). doi:10.1172/JCI33569.
Knockdown of Hip1r by RNAi in HeLa cells reduced receptormediated transferrin uptake, consistent with a critical function in endocytosis (8). In addition, the Hip1r-depleted cells had abnormal intracellular membrane structures, including Golgi with an increased number of clathrin-coated buds, as well as enlarged lysosomes. There was a general disorganization of the actin cytoskeleton in the Hip1r-depleted cells, with stable association of F-actin with clathrin-coated membrane structures. The changes in cell morphology in the Hip1r knockdown cell studies suggested that Hip1r plays a global role in regulating actin and membrane dynamics. Furthermore, overexpression of both Hip1 and Hip1r has previously been shown to stabilize growth factor receptors on the cell surface (9). This is the putative mechanism of transformation by Hip1 when overexpressed in certain human cancers (6).

Defining the specific in vivo cellular functions for Hip 1 family proteins, especially Hip $1 r$, has been elusive. Hip $1 r$-deficient mice are viable and fertile, with no obvious morphological abnormalities (10). Moreover, in contrast to the marked changes in vesicular trafficking shown in knockdown experiments in cultured HeLa cells $(5,8)$, clathrin trafficking pathways were normal in mouse embryonic fibroblasts isolated from either Hip1rdeficient mice or mice deficient in both Hip1 and Hip1r (10, 11), thus calling into question the in vivo importance of these proteins for clathrin-mediated vesicular trafficking. The similar protein structures and broad cell and tissue distribution of Hip1 and Hip1r raise the possibility that Hip1 could compensate for the loss of Hip1r in vivo. Compensation between Hip family members has been demonstrated by the accelerated and more severe phenotypes in double-mutant mice $(10,11)$. However, the 
A
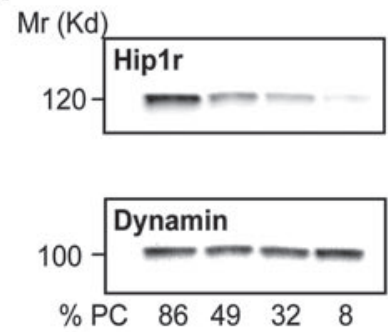

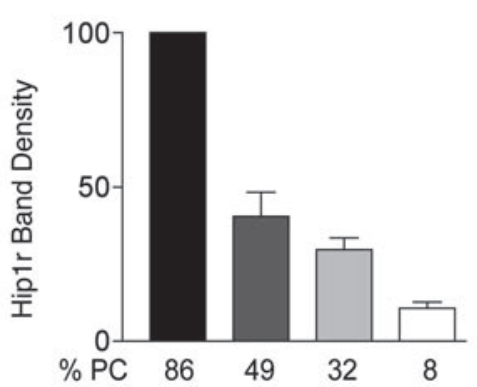

B F-actin

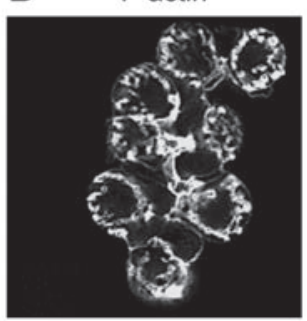

C

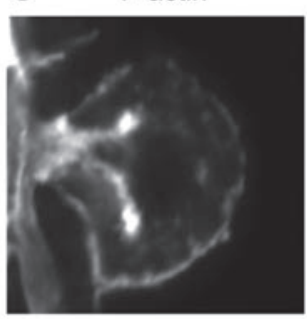

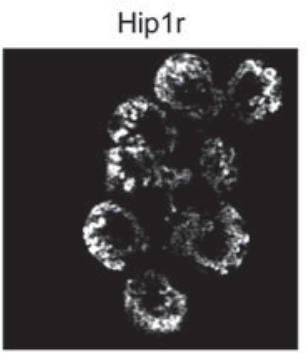

Hip1r

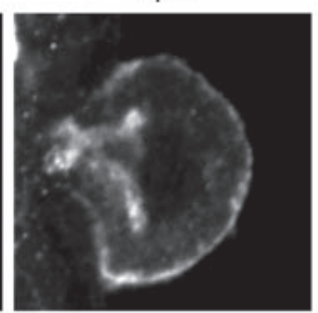

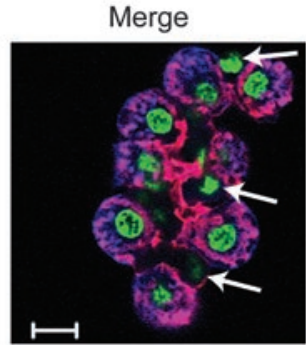

Merge

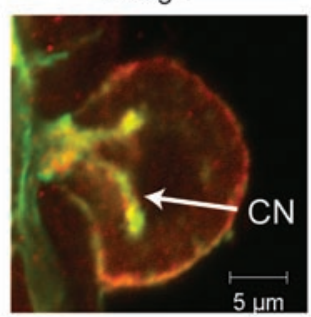

\section{Figure 1}

Hip1r is highly expressed in parietal cells, colocalizing with F-actin on the apical canalicular membrane. (A) Rabbit gastric mucosal cells were dispersed and fractionated by density gradient centrifugation, with parietal cell representation (\%PC) in each fraction determined by $\mathrm{H}^{+}, \mathrm{K}^{+}$-ATPase immunostaining. Shown are representative Western blots of gastric cell fractions that were sequentially probed for Hip1r and dynamin, a protein ubiquitously expressed in gastric mucosal cells. Quantitation from 3 blots in which independent parietal cell enriched/depleted fractions were analyzed is shown. Data (mean \pm SEM) are shown as band density, normalized to dynamin, relative to expression in the fraction containing the highest proportion of parietal cells. (B) Mouse gastric glands isolated from 3-month-old WT mice were costained for F-actin (red) and Hip1r (blue). Nuclei were visualized with SYTOX green. Shown is 1 gland with numerous parietal cells, demonstrating substantial coincidence of Hip1r and F-actin. Arrows denote nuclei of nonparietal cells, which did not stain with the Hip1r antibody. (C) Single parietal cell from a rabbit gastric gland preparation costained for F-actin (green) and Hip1r (red). Note their close correspondence in the apical canalicular and basolateral membranes. $\mathrm{CN}$, canalicular network. Scale bars: $10 \mu \mathrm{m}(\mathrm{B}) ; 5 \mu \mathrm{m}$ (C). double-mutant analysis did not uncover novel phenotypes that might be more directly related to Hip1r cellular function; thus, an in vivo role for Hip1r has not yet been defined.

Western blot analysis demonstrated that Hip1r is abundantly expressed in the stomach (10). This is interesting in light of the dynamic vesicular turnover known to occur in gastric parietal cells. The regulation of gastric acid secretion from the parietal cell into the lumen of the stomach involves regulated insertion of the $\mathrm{H}^{+}, \mathrm{K}^{+}$ATPase proton pump in and out of the apical secretory membrane. In resting cells, the proton pump resides in an extensive intracellular tubulovesicular compartment. Upon ingestion of a meal, gastric acid secretion is induced by the concerted actions of the hormone gastrin, the paracrine agent histamine, and the neurotransmitter acetylcholine (12). Upon stimulation of the parietal cell, tubulovesicles fuse with the apical plasma membrane to form an expanded surface membrane termed the canaliculus, which is capable of acid secretion into the lumen of the stomach. To return the parietal cell to the basal state, tubulovesicles containing the proton pump are reformed through a process thought to involve clathrin-coated vesicle formation similar to endocytosis (13). Thus, parietal cells rely on vesicular fusion and reformation to regulate acid secretion. Abundant expression of Hip1r in the stomach (10) raised the question of whether this protein is involved in the regulated vesicular trafficking in parietal cells associated with the secretion of gastric acid.

In this study, we examined the functional role of Hip1r in parietal cells. We demonstrated that Hip1r was abundantly expressed in the parietal cell, localized with F-actin to secretory canalicular membranes. Hip1r provides a critical function in vivo, as demon- strated by the loss of tubulovesicles, abnormal canalicular structure, and parietal cell apoptosis in Hip1r-deficient mice. Associated with the loss of parietal cell function was a multifaceted and progressive cellular transformation of the glandular epithelium of mutant mice, including a gross hypertrophy. Thus, we showed specific defects in gastric parietal cells in Hip1r-deficient mice consistent with a critical role for this protein in vesicular trafficking as well as secondary changes to the gastric mucosa resulting from parietal cell dysfunction and reduced acid secretion.

\section{Results}

Hip1r is expressed in gastric parietal cells. To determine the cellular localization of Hip1r in the stomach, epithelial cells from the acidsecreting region were fractionated by density gradient centrifugation and examined for Hip1r expression by Western blot analysis. Hip1r levels closely paralleled the parietal cell content in each fraction, with highest levels in the fraction containing $86 \%$ parietal cells and lowest levels in the $8 \%$ parietal cell fraction (Figure 1A). The pattern of Hip1r expression was distinct from dynamin, which was uniformly expressed in the various gastric mucosal cell fractions (Figure 1A). Specific localization of Hip1r to parietal cells was further demonstrated by costaining gastric gland preparations with an $\mathrm{Ab}$ to Hip1r and with phalloidin to visualize F-actin (Figure 1B). Parietal cells were clearly identified by their distinct morphology and extensive F-actin staining of the expansive canalicular membrane. The Hip1r staining showed correspondence with the parietal cell F-actin staining, with no staining observed in the other gastric cell types (Figure 1B). This result demonstrates 

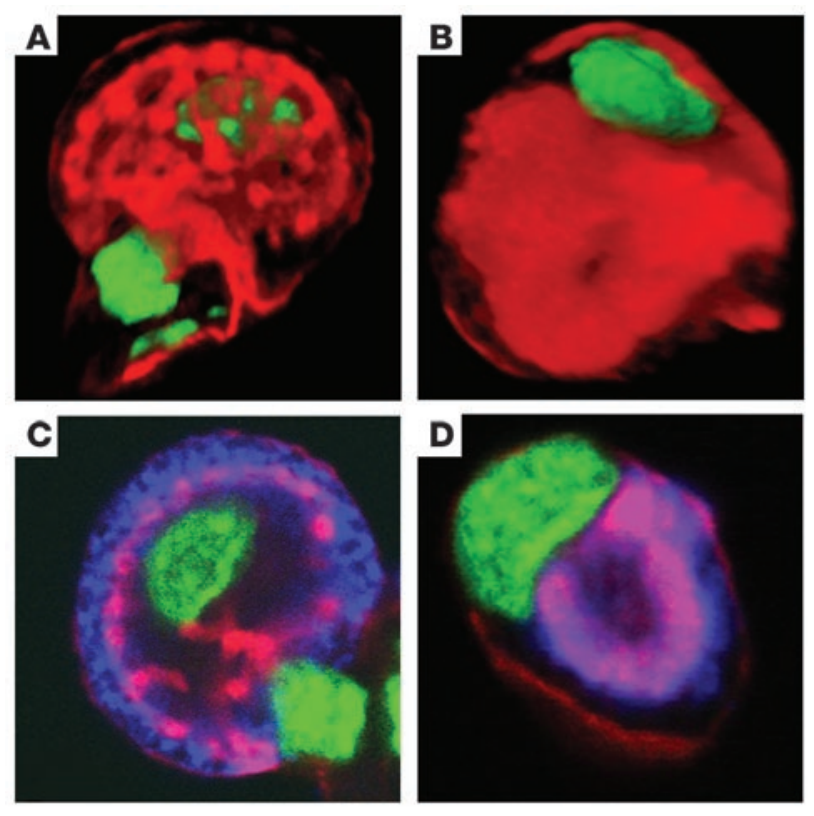

that Hip1r expression is limited to the parietal cells in this region of the gastric epithelium. There was close correspondence of Hip1r and F-actin staining, including expression on the cell membrane and canalicular membrane of the parietal cell (Figure 1C).

Abnormal secretory membranes in Hip1r-deficient parietal cells. To determine the importance of Hip $1 \mathrm{r}$ for parietal cell function, we examined mice with a targeted Hip1r gene mutation (10). These mice are viable and fertile, with no obvious morphological abnormalities (10). Previous studies on these mice did not include analysis of parietal cells or gastric physiology, so it was unknown how the absence of Hip1r affected stomach function. F-actin staining of mouse gastric gland preparations followed by confocal microscopic analysis and 3-dimensional reconstruction showed substantial changes to the parietal cell canalicular membrane in the mutant cells (Figure 2). Although continuous with the apical cellular membrane, the canalicular network in WT mice was visualized by F-actin staining as an elaborate branching structure in the parietal cell (Figure 2A). In contrast, the canaliculus in mutant parietal cells exhibited substantially less branching and thicker structure (Figure $2 \mathrm{~B}$ ). In addition, the position of the canaliculus within the cell appeared altered, with F-actin staining located closer to the nucleus and further from the basolateral membrane. Costaining for $\mathrm{H}^{+}, \mathrm{K}^{+}$-ATPase and F-actin demonstrated abnormal localization of the proton pump in the mutant parietal cells, with distribution around the condensed canaliculus (Figure 2, C and D). Furthermore, the $\mathrm{H}^{+}, \mathrm{K}^{+}$-ATPase distribution did not change after histamine treatment, in contrast to WT parietal cells, in which proton pumps redistributed to the canaliculus upon stimulation (data not shown).

Parietal cell ultrastructure was examined by transmission EM to characterize the changes in the canalicular structure and to examine tubulovesicles. Unstimulated WT parietal cells contained numerous intracellular tubulovesicles in addition to the apical canalicular network (Figure 3, A and B). Upon histamine stimulation of acid secretion, the tubulovesicles disappeared with expansion of the canaliculus as a result of tubulovesicular fusion with this apical secretory membrane (Figure 3C). At high-

\section{Figure 2}

Abnormal canalicular structure in parietal cells from Hip1r-deficient mice. Canalicular membranes in 3-month-old WT (A and $\mathbf{C}$ ) and Hip1rdeficient (B and $\mathbf{D})$ mouse gastric gland preparations. Nuclei were visualized with SYTOX green. (A and B) Three-dimensional confocal reconstructions from single parietal cells, visualized by staining for F-actin (red). ( $\mathbf{C}$ and $\mathbf{D}$ ) Confocal sections from single parietal cells, visualized by costaining for $\mathrm{F}$-actin (red) and $\mathrm{H}^{+}, \mathrm{K}^{+}$-ATPase $\alpha$ subunit (blue).

er magnification it was clear that the cytoplasm of the acutely stimulated cells was filled with canalicular, not tubulovesicular, membranes (Figure 3, compare B and D). In contrast to these features in WT cells, the unstimulated parietal cells of Hip1r-deficient mice had an extensive canalicular membrane and no tubulovesicles (Figure 3, E and F). In addition, there was no apparent structural change upon histamine stimulation (Figure 3, G and $\mathrm{H})$. Thus, the vesicular structure of unstimulated Hip1r-deficient parietal cells is similar to stimulated WT cells, with no tubulovesicles and expanded canalicular membranes. Moreover, the Hip1r-deficient parietal cells showed fewer canalicular branches (Figure 3 and data not shown), consistent with the results of the confocal microscope analysis (Figure 2).

Altered acid secretion dynamics in gastric glands from Hip1r-deficient mice. The dramatic structural alterations in the parietal cell actin cytoskeleton suggested that acid secretion would be affected in the mutant. We first examined acid production in isolated gastric gland preparations by measurement of accumulation of the weak base $\left[{ }^{14} \mathrm{C}\right]$-aminopyrine $\left(\left[{ }^{14} \mathrm{C}\right]-\mathrm{AP}\right)$, which partitions into acidic intracellular canaliculi (Figure 4). Values were similar in unstimulated (i.e., ranitidine-treated) gastric glands isolated from Hip1rdeficient and control mice, which suggests that resting acid levels were relatively normal in the mutant. However, there was a marked difference in the response to histamine stimulation, with increased rate and magnitude of AP ratios in Hip1r-deficient glands (Figure $4 \mathrm{~A})$. This result suggests that either acid production is increased in Hip1r-deficient parietal cells in response to histamine or the rate of acid loss from the cells into the media is reduced. To test the rate of acid leak from the glands, histamine-stimulated cells were treated with ranitidine to block acid production, and the rate of AP decay was measured (Figure 4B). Intracellular acid was released much slower from the mutant glands $\left(t_{1 / 2}, 17.1 \mathrm{~min}\right)$ compared with WT glands $\left(t_{1 / 2}, 7.2 \mathrm{~min}\right)$, suggesting that acid was trapped inside the Hip1r-deficient parietal cells with slow release into the media. We hypothesized that alterations in the canalicular structure and the actin cytoskeleton are responsible for the slower acid leak from Hip1r-deficient parietal cells.

Decreased acid secretion and loss of parietal cells in Hip1r-deficient mice. The in vivo consequences of these parietal cell changes were studied in Hipr1r-deficient mice. Measurement of gastric acid content in resting and histamine-stimulated stomach demonstrated a marked decrease in gastric acidity in the mutant. In contrast to WT mice, which showed a robust increase in acid upon histamine simulation, acid content was similar in untreated and histaminetreated Hip1r-deficient mice (Figure 5A). This result is consistent with our ultrastructural analysis, which showed no change in the secretory membranes of mutant parietal cells after histamine stimulation (Figure 3 and data not shown). However, the lack of a histamine response differs from the findings of acid production in isolated glands, where enhanced $\left[{ }^{14} \mathrm{C}\right]$-AP uptake was observed after histamine stimulation (Figure 4A). 

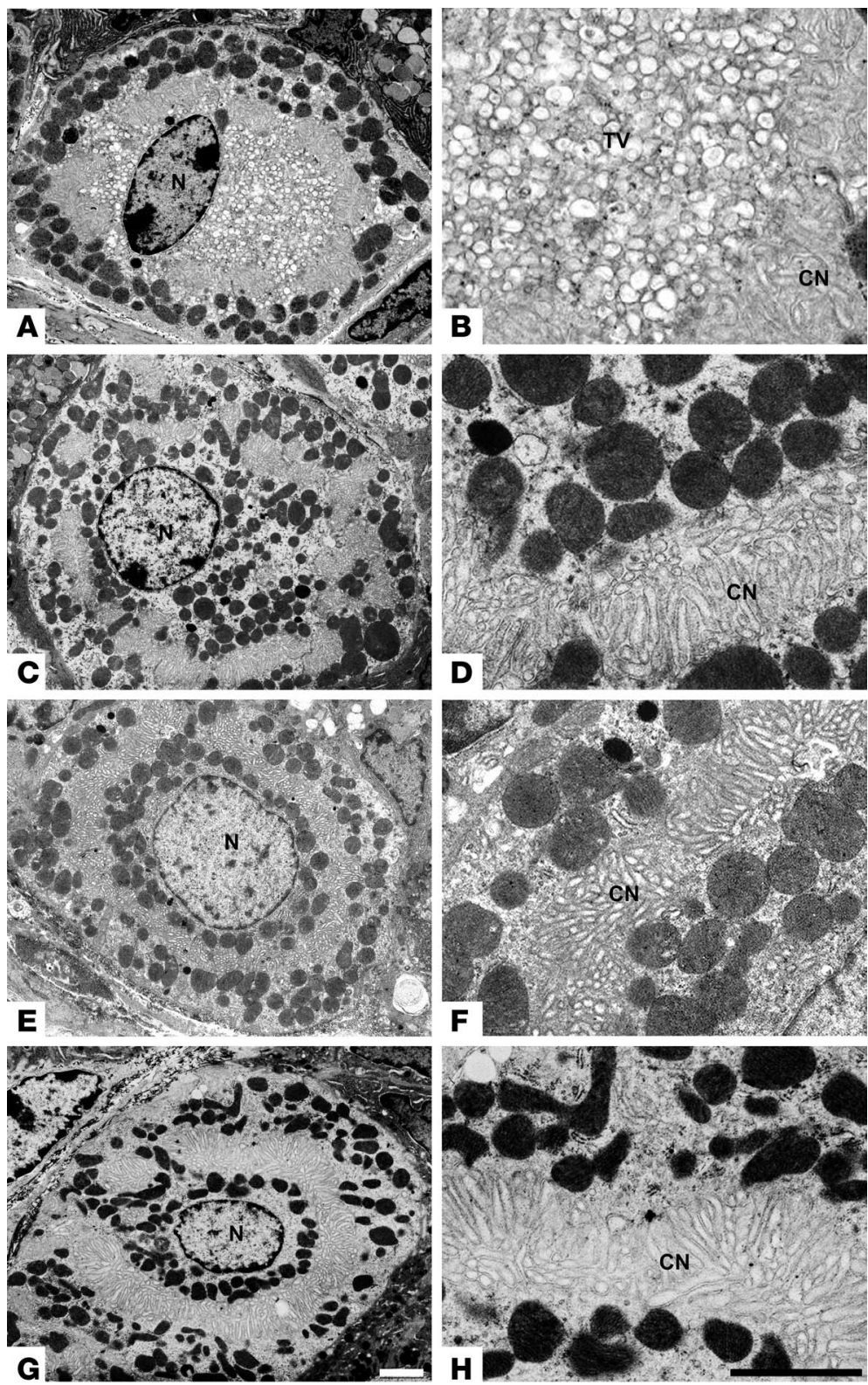

Figure 3

Parietal cells from Hip1r-deficient mice do not contain tubulovesicles. Transmission EM was used to examine parietal cell ultrastructure in 2-month-old WT (A-D) and Hip1r-deficient (E-H) mice. Mice were fasted overnight, with or without histamine treatment to stimulate acid, and tissues were processed to assess resting $(\mathbf{A}, \mathbf{B}, \mathbf{E}$, and $\mathbf{F})$ and stimulated $(\mathbf{C}, \mathbf{D}, \mathbf{G}$, and $\mathbf{H})$ vesicular structure. Note the absence of tubulovesicles in resting Hip1r-deficient cells ( $E$ and $\mathbf{F})$, which is similar to stimulated WT cells (C and D). TV, tubulovesicles; N, nucleus. Scale bars: $2 \mu \mathrm{m}$ (white, A, C, E, and G; black, B, D, F, and H).

Histological analysis of gastric paraffin sections showed numerous cellular changes in Hip1r-deficient mice compared with WT mice (Figure 5). The normally abundant parietal cells clearly visible in the WT mice were sparse in the mutant. In contrast to the WT section, with parietal cells as one of the most prominent cell types, Hip1r-deficient sections had very few recognizable parietal cells (Figure 5, D and $\mathrm{E}$ ). In addition, there were numerous delaminated cells in the Hip1r-deficient tissue (Figure 5E, arrowheads), which suggests that parietal cells were being removed from the gastric mucosa in the mutant. Parietal cell loss was confirmed by staining with an antibody to the parietal cell-specific $\alpha$ subunit of the $\mathrm{H}^{+}, \mathrm{K}^{+}$-ATPase proton pump (Figure 5, F and G). Although $\mathrm{H}^{+}, \mathrm{K}^{+}$-ATPaseexpressing cells were detected in the mutant, the staining was much lighter and revealed many distorted and fragmented cells (Figure 5, F and G). Abnormal parietal cells were also observed in younger Hip1r-deficient mice, with similar fragmentation apparent at 3 weeks of age (Figure 5, $\mathrm{H}$ and $\mathrm{I}$ ).

Parietal cell numbers were quantified by flow cytometric analysis of $\mathrm{H}^{+}, \mathrm{K}^{+}$-ATPase-stained gastric mucosal cell preparations. The proportion of parietal cells in the Hip1r-deficient gastric mucosa was reduced to $47 \%$ of normal (Figure 6A). Distorted and fewer parietal cells, and the presence of delaminated cells in the tissue, suggested that the mutant parietal cells were dying. Accordingly, TUNEL staining showed increased apoptosis in the Hip1r-deficient stomach (Figure 6, B and C). Furthermore, costaining for activated caspase- 3 and the parietal cell-specific marker $\mathrm{H}^{+}, \mathrm{K}^{+}$-ATPase demonstrated that all of the apoptotic cells in the mutant were parietal cells (Figure 6D).

The absence of Hip1r did not result in changes to the expression of the related family member Hip1 (Figure 7A). However, consistent with the approximately 50\% reduction in cell number, parietal cell markers were decreased in expression in Hip1r-deficient mice. Western blot analysis demonstrated reduced expression of the $\alpha$ subunit of $\mathrm{H}^{+}, \mathrm{K}^{+}$-ATPase (Figure 7A). Quantitative analysis of protein expression normalized to $\beta$-actin showed a $50 \%$ reduction in expression of this parietal cell-specific marker in Hip1r-deficient gastric mucosa (Figure 7A). This was confirmed at the RNA level with quantitative RT-PCR (qRT-PCR) analysis, showing approximately $60 \%$ decreases in mRNAs encoding the $\alpha$ and $\beta$ subunits of the proton pump (Figure 7B). A similar decrease was also observed in young (i.e., 3-weekold) Hip1r-deficient mice (data not shown). In addition to reduced proton pump expression, there was a similar $50 \%$ decrease in expression of parathyroid hormonelike hormone (Pthlh), another parietal cell marker (Figure 7B) (14). In contrast, protein expression of LIM and $\mathrm{SH} 3$ protein 1 (Lasp-1) and ezrin, cytoskeletal associated proteins that are not specific for parietal cells, were not significantly changed in the Hip1r-deficient mouse stomach (Figure 7A).

Glandular bypertrophy and mucous cell transformation in Hip1r-deficient mice. In addition to the parietal cell changes, there was extensive glandular hypertrophy in the Hip1rdeficient gastric mucosa (see Figure 5, B and C, shown at the same magnification). This was reflected in the gross stomach weight of the Hip1r-deficient mice, which increased 1.6-fold over WT controls $(0.36 \pm 0.015$ g vs. $0.20 \pm 0.008$ g; $P<0.0001$; $n=7$ per group). Analysis of H\&E-stained paraffin sections from 2-month-old mice showed that gastric gland height increased 2.1-fold compared with WT controls $(567 \pm 19.3 \mu \mathrm{m}$ vs. $264 \pm 18.8 \mu \mathrm{m}$; $P<0.0001 ; n=3$ per group). Analysis of young mice demonstrated that the hypertrophy was not apparent until 5 weeks of age (data not 
A

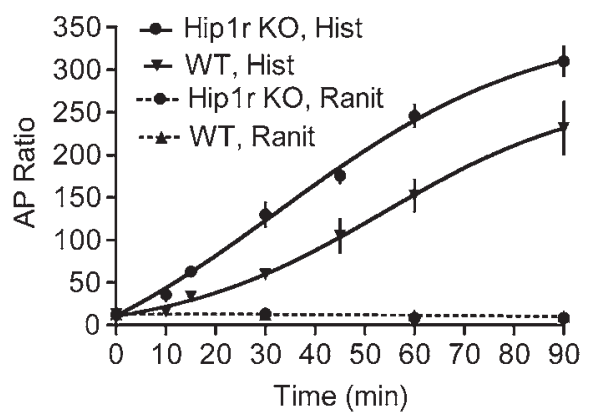

B

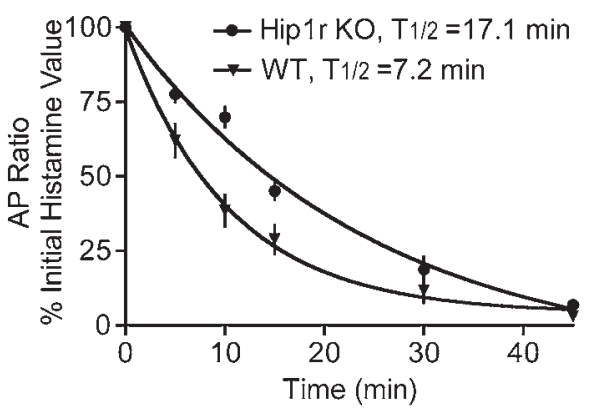

shown). In addition to the glandular hypertrophy, there were many cellular changes apparent from the H\&E-stained sections, including cystic structures (Figure 5C, arrow) and mononuclear inflammatory infiltrates in the submucosa and mucosa (Figure 5C, arrowheads).

Several other cellular changes were observed in the acid-secreting gastric mucosa of Hip1r-deficient mice. Analysis of H\&Estained paraffin sections suggested substantial loss of the chief (zymogenic) cells, located at the base of the gastric glands (Figure $5)$. This loss was confirmed by immunohistochemical staining with an antibody to the murine chief cell marker intrinsic factor (Figure 8, A and B). Measurement of intrinsic factor mRNA by qRT-PCR demonstrated a 4-fold decrease in abundance in Hip1r-deficient stomach, consistent with a loss of chief cells in this mutant (Figure 8C).

In contrast to the decreases in parietal and chief cells, there was expansion of an aberrant mucous cell population in the center portion of the gastric glands of the Hip1r-deficient mice. Mucous neck cells in the WT stomach stained lightly with PAS/Alcian blue, while the aberrant cells in the mutant stomach were filled with both neutral (pink) and acidic (blue) mucins (Figure 8, D and E). These aberrant mucous cells also stained strongly with Griffonia simplicifolia lectin II (GSII; Figure 8F), suggesting that they are related to mucous neck cells, which were recognized by this lectin in the normal mucosa (data not shown). In addition to the expansion of aberrant mucous neck-like cells in the center portion of the gland, we observed an expansion of surface mucous cells as well as a 2-fold increase in the expression of the surface mucous cell marker trefoil factor 1 (ref. 15 and data not shown). Thus, a general mucous cell hyperplasia appears to be the cause of the glandular hypertrophy in Hip1r-deficient mice.

Hypertrophy in Hip1r-deficient mice is gastrin dependent. Expression of the hormone gastrin was examined as a potential candidate for mediating the mucosal hypertrophy in Hip1r-deficient mice. Gastrin is known to be a growth factor for the acid-secreting mucosa, with hypergastrinemia leading to glandular hypertrophy (16). Gastrin mRNA abundance, as determined by qRT-PCR, increased

\section{Figure 4}

Time course for activation and inhibition of $\left[{ }^{14} \mathrm{C}\right]-\mathrm{AP}$ accumulation in gastric glands isolated from 3-month-old WT and Hip1r-deficient mice. (A) Glands were stimulated with $10 \mu \mathrm{M}$ histamine (Hist) or incubated with $50 \mu \mathrm{M}$ ranitidine (Ranit), and samples were taken at the indicated times. The ratios of $\left[{ }^{14} \mathrm{C}\right]-\mathrm{AP}$ accumulated in glands versus extracellular medium are shown as mean \pm SEM. $n=8-10$ mice per each of 4 experiments. (B) Glands were stimulated with $10 \mu \mathrm{M}$ histamine for $60 \mathrm{~min}, 50 \mu \mathrm{m}$ ranitidine was added, and samples were taken at the indicated times thereafter to measure the decay in $\left[{ }^{14} \mathrm{C}\right]$-AP retention. Values (mean \pm SEM) are shown as percent of the initial histaminestimulated value. $n=8-10$ mice per each of 3-4 experiments.

3-fold in Hip1r-deficient mice (Figure 9A). This increase was paralleled by an increase in circulating hormone, with RIA showing a 2.7-fold increase in plasma gastrin levels in the Hip1r-deficient mice compared with WT mice (Figure 9B).

We tested the role of gastrin in the cellular changes in Hip1r-deficient mice by crossing this mutant to gastrin-deficient mice. Gastrin-deficient mice were previously described to have reduced acid secretion, but the general cellular composition of the gastric glands was largely unchanged (17). Analysis of H\&E-stained paraffin sections showed that the mucosal height returned to control levels in the double-mutant mice, with gastric gland depth similar to that of WT controls (Figure 10, A-C). Measurement of proliferation in the Hip1r-deficient mice by Ki67 immunostaining showed a marked increase compared with WT mice (Figure 10, J-L). In contrast, the Ki67 immunostaining in Hip1r and gastrin double-mutant mice was similar to that of WT mice, indicating that normalization of gland height was caused by normalization of proliferation. However, $\mathrm{H}^{+}, \mathrm{K}^{+}$-ATPase immunostaining showed that parietal cells were still abnormal in the Hip1r and gastrin double-mutant mice, which suggests that the morphological changes were intrinsic cellular defects caused by the loss of Hip1r (Figure 10, D-I).

Analysis of the ultrastructure of Hip1r and gastrin double-mutant mice by transmission EM showed defects similar to those observed in the Hip1r-deficient parietal cells, with loss of tubulovesicles and expanded canalicular membranes (Figure 11, A and B). In addition, increased TUNEL staining in the Hip1r and gastrin double-mutant mice demonstrated apoptotic cell death similar to that of the single mutant (Figure 11C). Furthermore, the apoptotic cells were demonstrated to be parietal cells by costaining with Abs to activated caspase- 3 and $\mathrm{H}^{+}, \mathrm{K}^{+}$-ATPase (Figure $11 \mathrm{C}$, bottom inset). Thus, the activated morphology and parietal cell death resulting from the Hip1r mutation does not depend on gastrin stimulation.

\section{Discussion}

This study demonstrates, for the first time to our knowledge, multifaceted changes to the stomach of Hip1r-deficient mice. Hip1r was previously demonstrated to be expressed at high levels in the stomach (10). Here we showed that in the oxyntic mucosa, Hip1r was limited to the gastric parietal cell, associated with the specialized canalicular secretory membranes in these cells. These membranes are rich in F-actin, and Hip1r colocalization with F-actin is consistent with the previously described actin binding mediated by the talin-HIP1/R/Sla2p actin-tethering C-terminal homology (THATCH) domain near the $\mathrm{C}$ terminus of Hip1r $(18,19)$. Parietal cells regulate acid secretion by secretagogue-dependent trafficking of the proton pump from tubulovesicles to the apical canalicular membrane (20). Once the proton pump is localized at the apical 

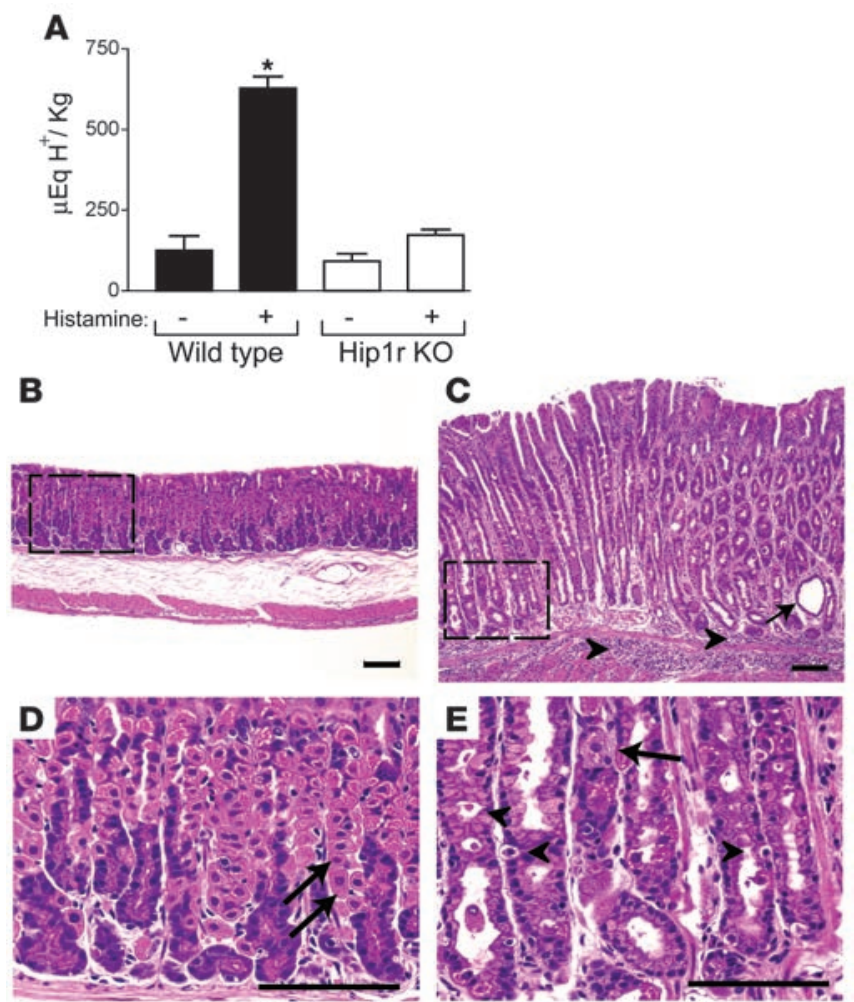

$\mathbf{F}$
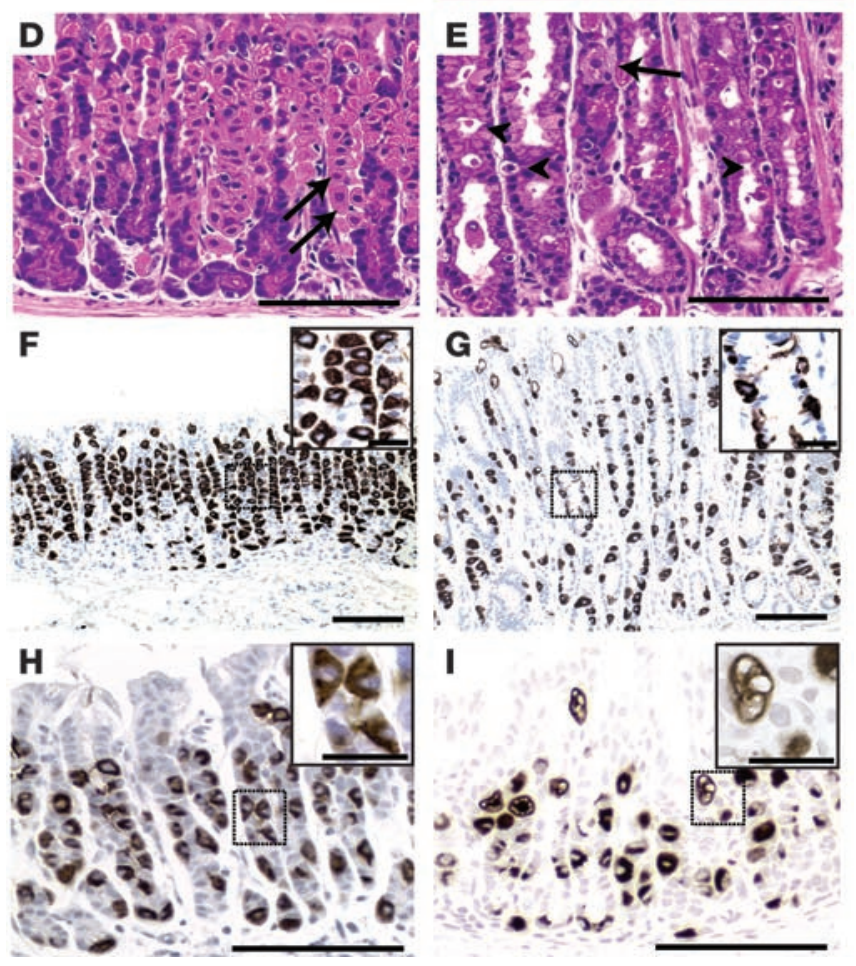

membrane, acid secretion into the lumen of the stomach takes place. Upon return to the resting state, proton pumps are sequestered back into tubulovesicles, a process thought to involve clathrin-coated vesicle formation similar to endocytosis $(13,21)$. Previous gene expression microarray studies of purified parietal cells showed abundant expression of Hip1r but little or no Hip1 (14), suggesting that Hip1r may serve a unique function in parietal cells. The importance of Hip1 $\mathrm{r}$ for normal vesicular trafficking in parietal cells was demonstrated in the present study by the abnormal canalicular network and loss of tubulovesicles in Hip1r-deficient parietal cells. The ultrastructural changes indicate a lack of formation or of reestablishment of tubulovesicles in the Hip1r-deficient parietal cell, processes both likely to involve clathrin-mediated vesicular trafficking. Thus, these in vivo data are consistent with previous in vitro studies showing disrupted clathrin-mediated endocytosis and

\section{Figure 5}

Reduced acid secretion and gross histological changes in Hip1r-deficient mouse stomach. (A) Acid content from the stomachs of 2- to 4month-old WT and Hip1r-deficient mice. Values (mean \pm SEM) were normalized to body wt. Mice were fasted ( $n=6$ per genotype) or treated with histamine ( $n=3$ per genotype) to measure basal and stimulated acid contents, respectively. ${ }^{*} P<0.005$ versus unstimulated WT. (B-G) Histological analysis of gastric paraffin sections from 2-month-old WT (B, D, and F) and Hip1r-deficient (C, E, and G) mice after H\&E staining (B-E) or $\mathrm{H}^{+}, \mathrm{K}^{+}-$ATPase immunostaining ( $\mathbf{F}$ and $\left.\mathbf{G}\right)$. H\&E staining revealed a hypertrophic mucosa in Hip1r-deficient mice with cystic structures (C, arrow) and inflammatory cell infiltrates (C, arrowheads). ( $\mathbf{D}$ and $\mathbf{E}$ ) Higher-magnification views of boxed regions in $\mathbf{B}$ and $\mathbf{C}$, respectively, demonstrate the marked cellular changes in Hip1r-deficient mice, including numerous delaminated cells (E, arrowheads). In comparison to the abundant parietal cells (arrows) in WT mice, only 1 recognizable parietal cell was seen in Hip1r-deficient mice. (F and $\mathbf{G}$ ) Sections stained for parietal cells with a mAb to the $\alpha$ subunit of $\mathrm{H}^{+}, \mathrm{K}^{+-}$ ATPase. Insets show higher-magnification images of boxed regions. $(\mathbf{H}$ and I) Similar analysis of 3-week-old WT $(\mathbf{H})$ and Hip1r-deficient (I) mice by $\mathrm{H}^{+}, \mathrm{K}^{+}$-ATPase immunostaining demonstrated parietal cell abnormalities in young mice. Scale bars: $100 \mu \mathrm{m}$ (B-I); $20 \mu \mathrm{m}$ (F-I, insets).

vesicle formation in cultured cells depleted of Hip $1 \mathrm{r}$ by RNAi (5, 8). Our present results support the conclusion that Hip1r is necessary for formation and/or trafficking of tubulovesicles in parietal cells. The necessity of Hip1 family proteins for clathrin-mediated vesicle trafficking appears to be cell specific, because endocytosis appeared normal in embryonic fibroblasts isolated from mice with gene mutations in both Hip1 and Hip1r $(10,11)$.

Parietal cell function in Hip1r-deficient mice was grossly altered by the loss of Hip1r. Histamine treatment robustly enhanced $\left[{ }^{14} \mathrm{C}\right]-$ $\mathrm{AP}$ accumulation in the mutant gastric glands. This result suggests that acid secretion is not strictly regulated by the trafficking of the proton pump in and out of the canalicular membrane, because there were no apparent vesicular changes after histamine stimulation. The notion that acid secretion does not depend solely on regulating movement of the proton pump in and out of the apical membrane was previously demonstrated from analysis of a transgenic mouse strain with a $\mathrm{H}^{+}, \mathrm{K}^{+}$-ATPase $\beta$ subunit mutation in the clathrin endocytosis signal (22). Similar to the Hip1r-deficient mutant studied herein, parietal cells in the previously described transgenic mouse lack a tubulovesicular compartment, and the proton pump is stably resident on the canalicular membrane (22, 23 ). The $\beta$ subunit mutant mouse responds to histamine stimulation with increased acid production, thus suggesting that regulation of other processes, such as apical $\mathrm{K}^{+}$and $\mathrm{Cl}^{-}$ion flow, are also critical for induction of gastric acid (23).

Histamine stimulation gave apparently contrasting results in vitro and in vivo. Robust histamine responses were observed in isolated gastric glands, while it did not increase gastric acidity measured in Hip1r-deficient stomach. The lack of response in the Hip1r-deficient mice in vivo may be a consequence of hypergastrinemia, with increased circulating gastrin fully stimulating the mutant stomach in the basal state to peak acid output. Moreover, in vitro analysis of secretion from isolated gastric glands suggested that acid produced in the mutant parietal cells may be trapped inside the cells, because the AP leak after ranitidine block was more than 2-fold slower than the leak from WT glands. Retention of acid within the cell would reduce acid release into the lumen of the gland and gastric acidity. The trapping of $\mathrm{HCl}$ in parietal cells would be expected to lead 


\section{A}
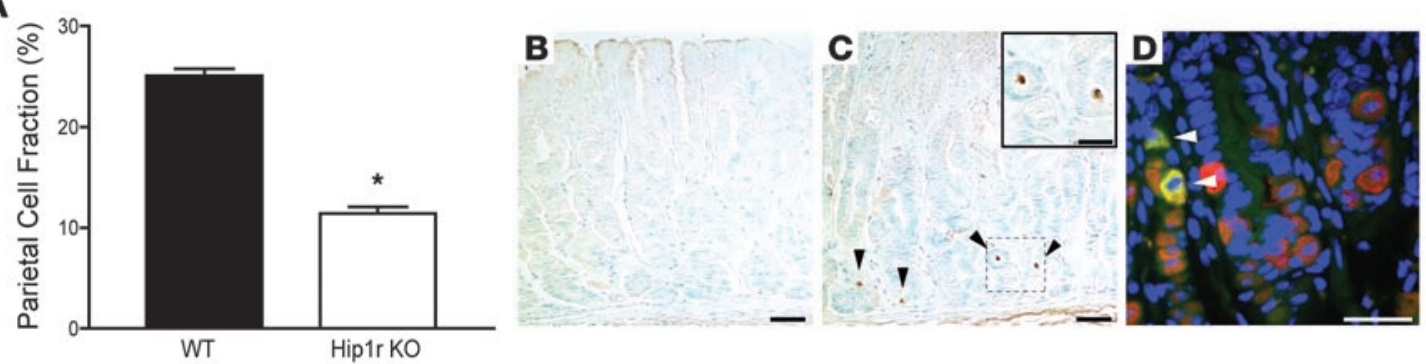

\section{Figure 6}

Decreased parietal cell number and increased parietal cell apoptosis in Hip1r-deficient mice. (A) Parietal cells $\left(\mathrm{H}^{+}\right.$, $\mathrm{K}^{+}-\mathrm{ATPase}$ positive) were measured as a proportion of total oxyntic epithelial cells (keratin positive) in 2-month-old WT and Hip1r-deficient mice by flow cytometry. Data (mean \pm SEM) are shown as percent parietal cell fraction. $n=3 .{ }^{*} P<0.0001$ versus WT. (B and C) TUNEL staining in 2-month-old WT (B) and Hip1r-deficient (C) mice. TUNEL-positive cells (arrowheads) were only observed in the mutant. (C, inset) Magnified view of the boxed region with 2 apoptotic cells. (D) Costaining for activated caspase-3 (green) and $\mathrm{H}^{+}, \mathrm{K}^{+}-\mathrm{ATPase}$ (red) in 2-month-old Hip1r-deficient stomach showed that the apoptotic cells were parietal cells (arrowheads). Scale bars: $40 \mu \mathrm{m}$ (B and C); $20 \mu \mathrm{m}$ (C) inset, and D).

to the formation of large vacuoles, such as those observed in the Hip1r-deficient mice, and prolonged and repeated accumulation of $\mathrm{HCl}$ could lead to cell damage and ultimately death.

Consistent with the 2 -fold decrease in the proportion of parietal cells in the oxyntic mucosa, Hip1r-deficient mice had approximately 2 -fold reduced expression of parietal cell markers. Moreover, $\mathrm{H}^{+}$, $\mathrm{K}^{+}$-ATPase immunostaining showed parietal cells with altered morphology, including cell fragments suggestive of cell death. The reduced parietal cell number was surprising because these mice are hypergastrinemic, which normally induces increased numbers of parietal cells (see below). We showed by TUNEL staining that there was increased apoptosis in the gastric mucosa of Hip1r-deficient mice. Moreover, we demonstrated that caspase-3-positive apoptotic cells costained for the parietal cell marker $\mathrm{H}^{+}, \mathrm{K}^{+}$-ATPase (Figure $6)$. Thus, the reduced number of parietal cells in Hip1r-deficient mice likely results from apoptotic cell loss, perhaps due to the trapped acid. Previous studies have demonstrated an association of hypergastrinemia with increased susceptibility of gastric epithelial cells to undergo apoptosis, including parietal cell apoptosis $(24,25)$. Thus, hypergastrinemia in Hip1r-deficient mice may play a role in the apoptotic loss of parietal cells. However, our observation that Hip1r and gastrin double-mutant mice also exhibited enhanced apoptosis (Figure 11) suggests that intrinsic loss of Hip1r from the parietal cell, not hypergastrinemia, is primarily responsible for cell death in these mice.

Functional studies of the related protein Hip1 suggest that loss of this family member can also induce apop-

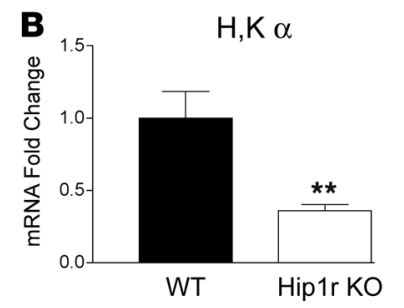

\section{Figure 7}

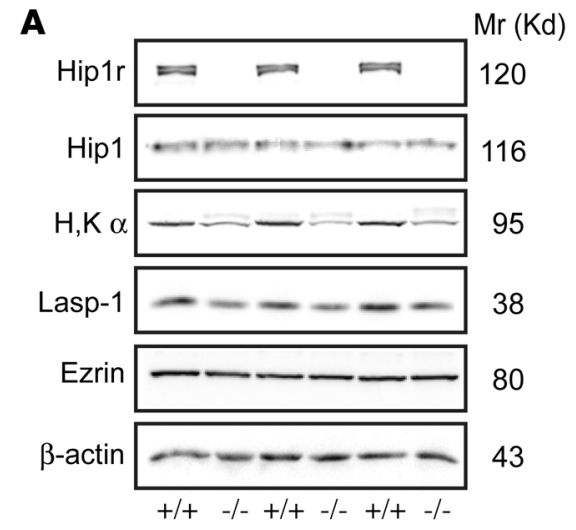

totic cell death. Hip1-deficient mice showed testicular degeneration with increased apoptosis of postmeiotic spermatids (26) and cataracts caused by cell death in the lens (27). In addition, caspase9-dependent apoptosis was observed when a dominant-negative Hip 1 construct was expressed in 293 T cells (28). The converse, a role for Hip1 in promoting cell growth or survival, is suggested by
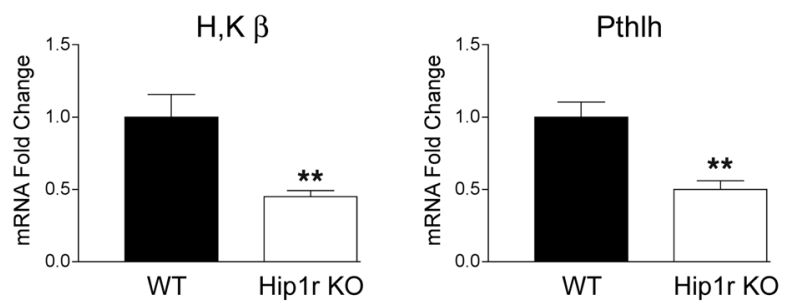

Reduced expression of parietal cell markers in Hip1r-deficient mouse stomach. (A) Western blot analysis of protein extracts from mucosal scrapings of gastric corpus from 3-month-old WT $(+/+)$ and Hip1r-deficient (-/-) mice. Extracts were subjected to SDS gel electrophoresis, and blots were probed with Abs to Hip1r; Hip1; $\mathrm{H}^{+}, \mathrm{K}^{+}-\mathrm{ATPase} \alpha(\mathrm{H}, \mathrm{K} \alpha)$; Lasp-1; ezrin; and $\beta$-actin. Quantitative measurement of the signal strength from extracts prepared from 3 different WT (black bars) and Hip1r-deficient (white bars) mice are shown as fold change relative to WT and normalized to $\beta$-actin as a loading control. Data are mean \pm SEM. (B) qRT-PCR analysis was used to measure parietal cell transcripts $\left(\mathrm{H}^{+}, \mathrm{K}^{+}\right.$-ATPase $\alpha, \mathrm{H}^{+}, \mathrm{K}^{+}$-ATPase $\beta$, and parathyroid hormone-like hormone [Pthlh]) in RNA samples isolated from the corpus of 6-month-old WT and Hip1r-deficient mice. Data (mean \pm SEM) were normalized to Gapdh expression in the same samples and reported as fold change relative to WT. $n=3 .{ }^{\star} P<0.05,{ }^{\star *} P<0.03$ versus WT. 

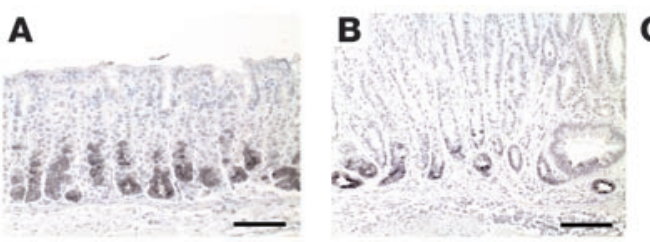

\section{을}
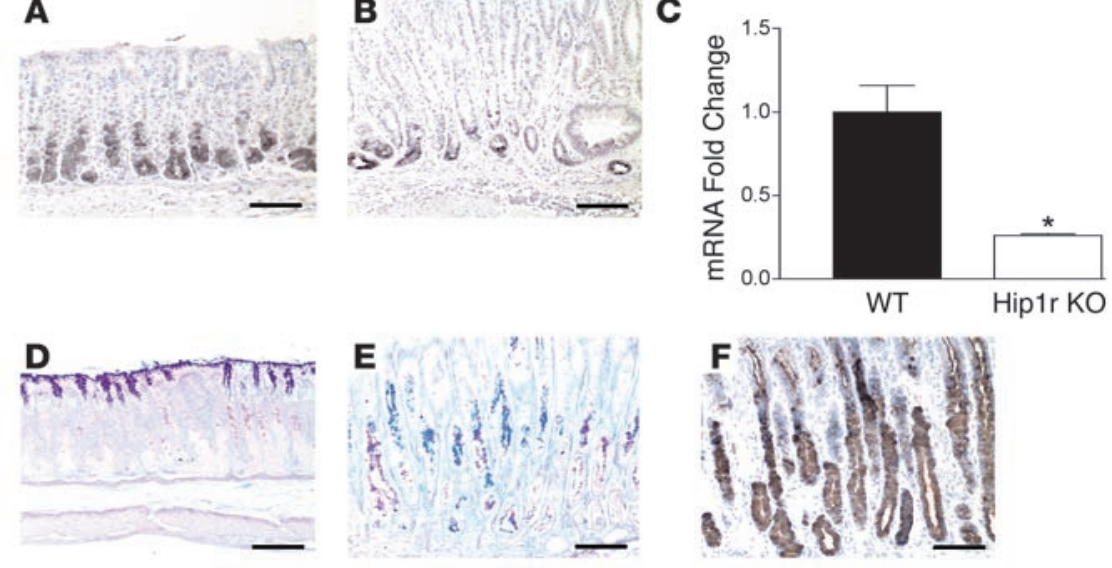

\section{Figure 8}

Loss of chief cells and expansion of an aberrant mucous neck cell population in Hip1r-deficient stomach. (A and B) Chief cells in 2-month-old WT (A) and Hip1r-deficient (B) mice were identified by immunostaining paraffin sections with a polyclonal antibody to intrinsic factor. (C) Intrinsic factor mRNA abundance was determined by qRT-PCR analysis of RNA samples isolated from the corpus of 6-month-old WT and Hip1r-deficient mice. Data (mean \pm SEM) were normalized to Gapdh expression in the same samples and reported as fold change relative to WT. $n=3$. ${ }^{*} P=0.01$ versus WT. (D-F) Expansion of aberrant mucous neck cells in Hip1r-deficient mice. Paraffin sections from 2-month-old WT (D) and Hip1r-deficient (E and F) mice were stained with PAS/Alcian blue (D and E) for neutral (pink) or acidic (blue) mucus or with GSII (F) to identify mucous neck cells. Scale bars: $100 \mu \mathrm{m}$.

increased Hip1 expression in numerous cancers $(6,28)$ as well as by increased cell survival in cultured cells overexpressing Hip 1 or Hip1r (29). These studies, together with our present results, suggest that both Hip1 and Hip1r can play critical roles for cell survival in specific cell types. It is important to note, however, that double-mutant mice with null mutations in both Hip1 and Hip1r are viable, although they do suffer from a number of defects, including spinal and hematopoietic abnormalities, testicular degeneration, and cataracts $(10,11)$.

Loss of parietal cells and reduced gastric acidity lead to a number of secondary changes in the gastric mucosa. Normally, acid secretion is highly regulated to maintain stomach $\mathrm{pH}$. The hormone gastrin is the primary regulator of meal-stimulated acid secretion (30). Gastrin levels are under feedback control, with synthesis and secretion regulated by changes in luminal stomach acid (31). We measured markedly higher gastrin mRNA and circulating gastrin in Hip1r-deficient mice, which is consistent with low gastric acid stimulating gastrin release as a compensatory response to maintain acid homeostasis. In addition to being a physiological inducer of acid secretion, gastrin has previously been recognized as a growth factor for the gastric mucosa (16). Gastrin overexpression in transgenic mouse models has been shown to induce mucosal proliferation, glandular hypertrophy, and increased numbers of parietal cells $(32,33)$. Thus, we tested whether hypergastrinemia in Hip1r-deficient mice was responsible for the gastric hypertrophy by crossing these mice to gastrin-deficient mice. The double-mutant mice normalized gastric gland height and cellular proliferation, demonstrating that mucosal hypertrophy in Hip1rdeficient mice was gastrin dependent. The importance of gastrin for inducing gastric hypertrophy in mouse mutants with low acid secretion has also been demonstrated in 2 previous studies. Mucosal depth was normalized in the achlorhydric $\mathrm{H}^{+}, \mathrm{K}^{+}$-ATPase $\beta$ subunit mutant when crossed to gastrindeficient mice (34) and in the hypochlorhydric histamine $\mathrm{H}_{2}$ receptor-deficient mutant when crossed to gastrin receptor-deficient mice (35). These previous studies, together with our present results, lead us to conclude that mouse mutants with intrinsic defects in the parietal cell leading to low acid secretion will increase gastrin as a compensatory mechanism and that hypergastrinemia will induce increased proliferation and hypertrophy of the gastric mucosa. Our studies also showed that altered parietal cell morphology in Hip1r-deficient mice was not dependent on gastrin, and therefore is not secondary to hyperstimulation of the parietal cell as a consequence of hypergastrinemia. Indeed, ultrastructural analysis of Hip1r and gastrin double-mutant parietal cells by transmission EM showed activated morphology similar to that observed in the single Hip1r mutant. Similarly, activated morphology was observed by EM analysis after treatment of Hip1r-deficient mice with an $\mathrm{H}_{2}$ receptor antagonist to block secretagogue stimulation (data not shown). We conclude that the lack of tubulovesicles is a primary consequence of the loss of Hip1r and is not caused by hyperstimulation.

The Hip1r-deficient mice exhibited a generalized cellular transformation of the gastric mucosa. Reduced numbers of parietal cells and chief cells were accompanied by an expansion in the number of mucous cells, including an aberrant mucous cell type that occupied the majority of the glands. The aberrant mucous cells in Hip1r-deficient mice stained with GSII, a mucous neck cell marker, which suggests that the observed cells are derived from this lineage. Chief cells are also derived from mucous neck cells, with differentiation occurring upon migration toward the base of the gastric gland $(36,37)$. Thus both the loss of chief cells and the expansion of an aberrant mucous neck cell lineage may involve a single switch in cellular differentiation. The aberrant mucous neck cells express features normally associated with mucous cells in


\section{Figure 9}

Hip1r-deficient mice are hypergastrinemic. (A) Gastrin transcript abundance was determined by qRT-PCR analysis of gastric antral RNA samples from 6-month-old WT and Hip1r-deficient mice. Data (mean \pm SEM) were normalized to Gapdh expression in the same samples and reported as fold change relative to WT. $n=3$. (B) Plasma gastrin levels were measured in 2- to 6-month-old mice by RIA in WT and Hip1r-deficient mice $(n=8-10) .{ }^{*} P<0.05,{ }^{* *} P=0.0001$ versus WT. 
Wild type

A
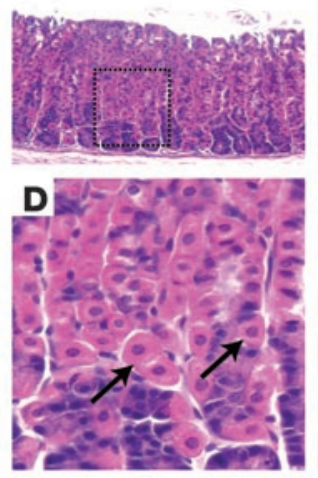

G
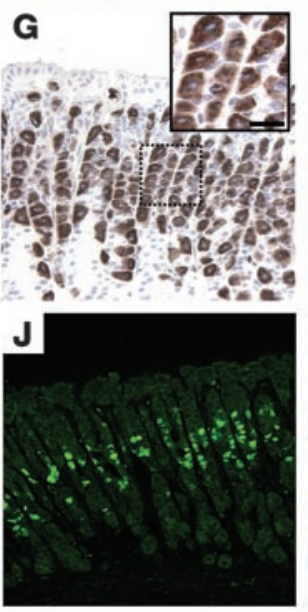

Figure 10

Gastric hypertrophy and hyperproliferation in Hip1r-deficient mice are gastrin dependent. Histological analysis of gastric paraffin sections from 2-month-old WT (A, D, G, and J), Hip1r-deficient (B, E, H, and K), and Hip1r and gastrin double knockout (DKO; C, F, I, and L) mice. (A-C) H\&E-stained paraffin sections showed a normalization of gland height when the Hip1 $r$ mutation was on a gastrin-deficient strain background. (D-F) Magnified view of boxed regions in H\&E-stained sections with parietal cells (arrows). (G-I) Immunostaining for $\mathrm{H}^{+}, \mathrm{K}^{+}$-ATPase. Insets are magnified views of boxed regions to show parietal cell morphology. (J-L) Ki67 immunostaining of paraffin sections showed normalization of proliferation when the Hip1r mutation was on a gastrin-deficient background. Scale bars: $50 \mu \mathrm{m}(\mathbf{A}-\mathbf{L}) ; 10 \mu \mathrm{m}$ (G-I, insets).

more distal regions of the gastrointestinal tract, such as the deep antral glands, Brunner glands, and intestinal goblet cells. Similar histopathology has previously been described in other mouse models with diminished parietal cell function (38-40) and has been associated with Helicobacter infection (41-43) as well as cellular transformation in the progression to gastric cancer in humans (44). The Hip1r-deficient mice are unusual in the penetrance and early appearance of this phenotype, which normally takes several months to mature in other mouse models and is widespread in the Hip1r mutants as early as 2 months of age.

The aberrant mucous cell lineage in the Hip1r-deficient stomach is similar to spasmolytic polypeptide-expressing metaplasia (SPEM), which occurs in response to loss of parietal cells and gastric inflammation (45). Inflammation was widespread in the Hip1r-deficient mouse stomach, with mononuclear infiltrates observed in the mucosa and submucosa. Previous studies of mouse models with low acid secretion, including gastrin-deficient mice and normal mice treated with a proton pump inhibitor, showed that bacterial overgrowth and inflammation develop in the hypochlorhydric stomach (46). Infusion of the proinflammatory Th1 cytokine IFN- $\gamma$ has been shown to induce a SPEMlike phenotype within 1-2 weeks $(45,47)$. We observed increased IFN- $\gamma$ in the stomachs of Hip1r-deficient mice as they aged (data not shown). Thus, the aberrant mucous cell expansion in Hip1r-deficient mice may result from gastric inflammation. Alternatively, because chief cell differentiation appears to require mature parietal cells, it is possible that parietal cells release a factor required for the transition from mucous neck cell to chief cell (48). Indeed, SPEM formation does not require inflammation, as shown by experiments where destruction of parietal cells with the drug DMP-777 induced SPEM in the absence of apparent gastritis (49). Because the Hip1r-deficient mouse stomach includes parietal cell dysfunction and inflammation, both loss of a parietal cell factor and inflammatory mediators may contribute to the SPEM-like transformation.

In summary, the results of the present studies have demonstrated that Hip1r in the acid-secreting gastric epithelium is expressed specifically in the parietal cell. Analysis of Hip1r-deficient mice showed that Hip1r was required for the formation of parietal cell tubulovesicles. The lack of parietal cell tubulovesicles was consistent with previous in vitro studies that demonstrated the importance of Hip1r for clathrin-mediated membrane trafficking. Thus, our study confirms that Hip1r plays an important role in vesicular trafficking in selected cell types in vivo. The functional changes to the parietal cells in Hip1r-deficient mice led to cellular transformation of the gastric mucosa, demonstrating the key role that parietal cells and gastrin play for physiology and pathophysiology of the stomach.

\section{Methods}

Animal use. Hip1r-deficient mice (10) and Hip1r-deficient and gastrin double-mutant mice (17) were on mixed 129X1 and C57BL/6 strain backgrounds. Mice were housed under specific pathogenfree conditions and fasted overnight, with free access to water prior to use. Mouse and rabbit use were approved by the University of Michigan and Medical College of Georgia Institutional Animal Care and Use Committees.

Gastric gland immunostaining and fractionation. Gastric mucosal cells were dispersed from the oxyntic mucosa of New Zealand White rabbits by sequential pronase and collagenase digestion, and cell fractions were separated by Optiprep density gradient centrifugation as described previously (50). The percentage of parietal cells in each fraction was calculated by immunostaining for $\mathrm{H}^{+}, \mathrm{K}^{+}$-ATPase ( $\alpha$ subunit, clone HK 12.18; Calbiochem).

Mouse gastric glands were isolated using a modification of the rabbit protocol. Mice were anesthetized (50 mg/ $\mathrm{kg}$ pentobarbital), and tissues were perfused with warm, oxygenated PBS by cardiac puncture. Gastric mucosae were scraped, minced, washed with DMEM/F12 medium without bicarbonate containing $0.2 \% \mathrm{BSA}$, digested in pronase $(0.25 \mathrm{mg} / \mathrm{ml} \mathrm{DMEM} / \mathrm{F} 12$; Calbiochem) for $5 \mathrm{~min}$ at $37^{\circ} \mathrm{C}$, washed, and digested with collagenase $(0.25 \mathrm{mg} / \mathrm{ml}$ DMEM/F12, Type II; Sigma-Aldrich) for 15-20 min. Reactions 


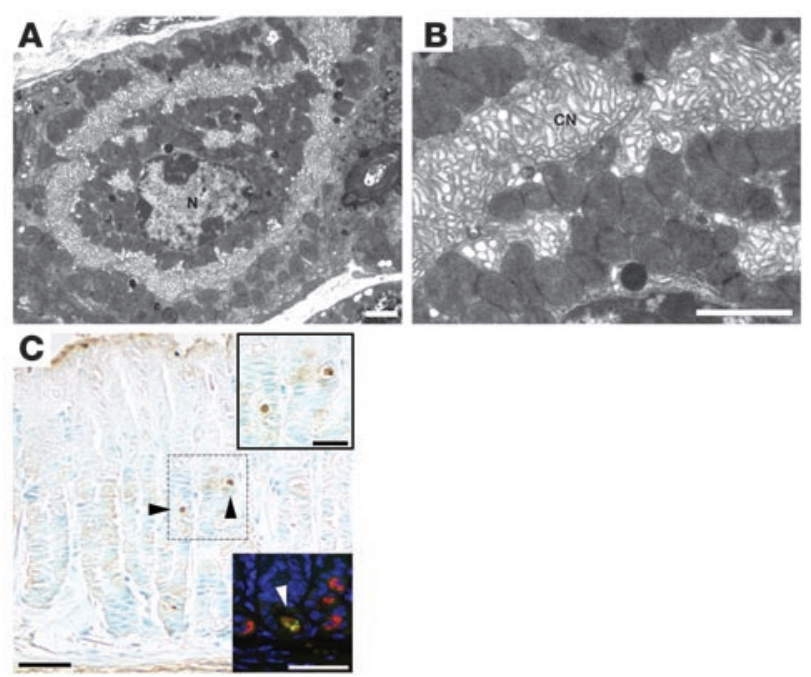

were terminated by addition of $50 \mathrm{ml} \mathrm{DMEM} / \mathrm{F} 12$ containing $0.2 \% \mathrm{BSA}$ and $1 \mathrm{mM}$ DTT. PFA fixation and immunostaining were performed as previously described (50, 51). The Hip1r mouse mAb (1:100; BD Biosciences) was diluted in tris-buffered saline containing $1 \%$ nonfat milk (BioRad). Donkey anti-mouse secondary antibody conjugated to Cy5 (1:100; Jackson ImmunoResearch Laboratories), SYTOX green ( $0.5 \mu \mathrm{M}$; Invitrogen), and Oregon green- or Alexa Fluor 568-conjugated phalloidin (1:40; Invitrogen) were diluted in tris-buffered saline with $0.1 \%$ nonfat milk. Stained glands were mounted with Prolong Gold antifade reagent (Invitrogen) and visualized with a Zeiss LSM 510 META confocal microscope using Meta software (version 3.2; Zeiss) (50). Controls for nonspecific binding and fluorescent emission crossover were included in each experiment as described previously (52). Three-dimensional images were generated using Volocity version 4.0.0 (Improvision; Mac OS X version 10.4.9).

Measurement of acid production in mouse gastric glands. Acid secretion was assessed indirectly in gastric glands isolated from 3-month-old WT or Hip1r-deficient mice using $\left[{ }^{14} \mathrm{C}\right]$-AP accumulation as previously described (53). After addition of $\left[{ }^{14} \mathrm{C}\right]-\mathrm{AP}$, glands were placed in $25 \mathrm{ml}$ Erlenmeyer flasks. The histamine $\mathrm{H}_{2}$-receptor antagonist ranitidine $(50 \mu \mathrm{M})$ was added to flasks to be used for basal measurements. Glands were temperature equilibrated $\left(10 \mathrm{~min}, 37^{\circ} \mathrm{C}\right.$, shaking water bath), and then $10 \mu \mathrm{M}$ histamine was added to flasks that did not contain ranitidine. For time course studies, $0.25-\mathrm{ml}$ aliquots were withdrawn from flasks at each time point. AP accumulation was expressed as the ratio of $\left[{ }^{14} \mathrm{C}\right]$-AP accumulated in glands to the amount in the extracellular medium, with correction for trapped volume as previously described (53). To determine rates of ranitidine inhibition, glands were incubated with and without $10 \mu \mathrm{M}$ histamine for $60 \mathrm{~min}$, at which time initial samples were taken and $50 \mu \mathrm{M}$ ranitidine was added. Samples were withdrawn at 5- to 15 -minute intervals, and AP accumulation was expressed as a percent of the initial values measured after response to histamine at $60 \mathrm{~min}$. Nonlinear curve fitting was performed with Prism software (version 4.0; GraphPad) using the Boltzmann sigmoidal equation and the 1 -phase exponential decay equation for activation and inhibition analyses, respectively.

Transmission EM analysis. WT, Hip1r-deficient, or Hip1r and gastric double-mutant mice were left untreated (basal) or treated with histamine (stimulated; $20 \mathrm{mg} / \mathrm{kg}$ in PBS) by i.p. injection $30 \mathrm{~min}$ prior to sacrifice. Fundic tissue strips were cut and fixed overnight at $4{ }^{\circ} \mathrm{C}$ in $2 \%$ glutaraldehyde plus $2 \%$ PFA in $0.1 \mathrm{M}$ sodium cacodylate buffer ( $\mathrm{pH} 7.4$ ), followed by washing in $0.1 \mathrm{M}$ sodium cacodylate buffer. Tissue was treated with

\section{Figure 11}

Abnormal parietal cell morphology and apoptosis in 2-month-old Hip1r and gastrin double-mutant mice. (A and $\mathbf{B}$ ) Transmission EM demonstrated a lack of tubulovesicles in unstimulated double-mutant parietal cells. The morphology was similar to the Hip1r mutant (compare with Figure 3, E and F). (C) TUNEL staining revealed apoptotic cells in the Hip1r and gastrin double-mutant stomach mucosa. Top inset: Magnified view of the boxed region with 2 apoptotic cells (arrowheads in $\mathbf{C}$ ). Bottom inset: Magnified view of a section costained for activated caspase-3 (green) and $\mathrm{H}^{+}, \mathrm{K}^{+}$-ATPase (red) to demonstrate parietal cell apoptosis. Scale bars: $2 \mu \mathrm{m}$ (A and B); $40 \mu \mathrm{m}$ (C); $20 \mu \mathrm{m}$ (C, insets).

$4 \%$ osmium tetroxide, washed in $0.1 \mathrm{M}$ sodium cacodylate buffer, briefly rinsed in deionized water, and dehydrated and stained with $2 \%$ uranyl acetate in $70 \%$ ethanol, followed by a graded ethanol series and embedding in Epon/Araladite using standard polypropylene oxide infiltration procedures. Sections ( $70-80 \mathrm{~nm}$ ) were stained with uranyl acetate and lead citrate and visualized with either a JEOL 1010 or a JEOL 1230 transmission EM equipped with a Gatan 16-megapixel digital camera. At least 25 parietal cells from 2 independent tissue sections obtained from each of 4 animals were analyzed for each genotype and treatment.

Gastric acid content. Stomachs from WT and Hip1r-deficient mice (2-4 mo of age), untreated $(n=6)$ or treated with histamine ( $n=3$; see above), were cut along the greater curvature, and contents were collected by rinsing in $2 \mathrm{ml}$ $0.9 \% \mathrm{NaCl}$ ( $\mathrm{pH} 7.0$ ). Acid content was measured by titration as described previously (39), and values were normalized to kg body wt. The body wt of Hip1r-deficient and WT mice did not differ.

Histological analysis. Stomachs were processed and fixed in 4\% PFA as described previously (39). Paraffin sections (3-5 $\mu \mathrm{m})$ were stained with $\mathrm{H} \& \mathrm{E}$ or PAS/Alcian blue, and gastric cell types were identified by immunostaining with a mouse $\mathrm{mAb}$ to the $\mathrm{H}^{+}, \mathrm{K}^{+}$-ATPase $\alpha$ subunit (1:500; Medical and Biological Laboratories) for parietal cells and a polyclonal antibody to intrinsic factor (1:2,000 rabbit anti-human intrinsic factor; gift from D. Alpers, Washington University St. Louis, St. Louis, Missouri, USA) for chief cells, or with GSII conjugated to biotin (1:1000; Vector Laboratories) for mucous neck cells. Staining and secondary antibody use was as previously described (39). Proliferating cells were recognized by staining with a rabbit polyclonal antibody to Ki67 (1:500; Novacastra) followed by a goat anti-rabbit secondary antibody conjugated to Alexa Fluor 488 (1:500; Invitrogen).

For TUNEL staining, we used the TACS TdT kit (R\&D Systems) according to the manufacturer's recommendations, with 45 min protease $\mathrm{K}$ treatment, $\mathrm{Co}^{2+}$ inclusion, and incubations at room temperature. Costaining for activated caspase- 3 and the proton pump was done by first incubating paraffin sections with a rabbit $\mathrm{mAb}$ to cleaved caspase-3 (1:50; Cell Signaling) overnight at $4^{\circ} \mathrm{C}$, followed by staining for $\mathrm{H}^{+}, \mathrm{K}^{+}$-ATPase $\alpha$ subunit (diluted 1:100) for $1 \mathrm{~h}$ at room temperature. Secondary $\mathrm{Ab}$ staining with goat antirabbit Alexa Fluor 488 (1:250; Invitrogen) and goat anti-mouse Cy3 (1:250; Jackson ImmunoResearch Laboratories) was performed simultaneously.

Protein analysis. Fundic homogenates from WT and Hip1r-deficient mice $(n=3)$ were prepared as described previously (14). Western blots were sequentially analyzed for the following proteins: Hip 1r (1:2,000; BD Biosciences), $\mathrm{H}^{+}, \mathrm{K}^{+}$-ATPase $\alpha$ (1:10,000, clone HK 12.18; Calbiochem), ezrin (1:10,000, clone A45; Covance), $\beta$-actin (1:10,000, clone AC74; SigmaAldrich), and Lasp-1 (1:2,000, clone 8C6). The Lasp-1 antibody was a mouse $\mathrm{mAb}$ (isotype IgG1, $45 \%$ ammonium sulfate precipitate) produced by the University of Georgia Monoclonal Antibody Facility using a KLHconjugated peptide (CKYHEEFEKSRMGPSGGEG) with antibody specificity validated as described previously (52). Hip1 (1:5,000 UM3223, rabbit polyclonal generated in our laboratory), which has a MW similar to Hip1r, 
was analyzed on separate Western blots. Species-appropriate HRP-conjugated secondary antibodies (sheep anti-mouse and donkey anti-rabbit, both 1:5,000) were used, and signals were detected by ECL and quantitated with a Syngene GeneGenome CCD-based system as described previously (51). Gastric mucosal cell fractions from rabbit were similarly analyzed by Western blot using Hip1r and dynamin (1:1,000, Dynamin I/II, clone N19; Santa Cruz Biotechnology Inc.) antibodies.

Flow cytometric quantification of parietal cells. Parietal cells from 2-monthold WT and Hip1r-deficient mice were quantified using a BD FACSVantage SE cell sorter as described previously (54). Briefly, gastric corpus was isolated from individual mice, and epithelial cells were dispersed with pronase, fixed, and permeabilized using the Cytofix/Cytoperm Kit (BD Biosciences - Pharmingen). Aliquots were incubated $20 \mathrm{~min}$ at $4^{\circ} \mathrm{C}$ with a mouse $\mathrm{mAb}$ against $\mathrm{H}^{+}, \mathrm{K}^{+}$-ATPase $\alpha$ subunit (1:1,000; Medical and Biological Laboratories) or with a rat $\mathrm{mAb}$ against cytokeratin-8 (1:500; Hybridoma Bank, University of Iowa) and appropriate secondary antibodies labeled with Cy2 (1:250; Jackson ImmunoResearch Laboratories). The proportion of $\mathrm{H}^{+}, \mathrm{K}^{+}$-ATPase-positive parietal cells in the cytokeratin-8positive epithelial cell population was calculated after analysis of 10,000 cells $(n=3$ per genotype).

qRT-PCR analysis. RNA was isolated from 6-month-old WT and Hip1rdeficient gastric corpus ( $n=3$ per genotype) as previously described (39). $\mathrm{RT}$ reactions were performed with Iscript transcriptase (BioRad) according to the manufacturer's instructions, and samples were tested in triplicate by qRT-PCR as described previously (14). Primer sequences were as follows: $\mathrm{H}^{+}, \mathrm{K}^{+}$-ATPase $\alpha$ and $\beta$ and Pthlh were previously described (14); intrinsic factor was previously described (38); gastrin, forward ACACAACAGCCAACTATTC, reverse CAAAGTCCATCCATCCGTAG.

Gastrin RIA. Blood was collected from 2- to 6-month-old fasted mice by cardiac puncture into heparinized tubes, and plasma was isolated and stored at $-20^{\circ} \mathrm{C}$ until assayed. Samples $(50 \mu \mathrm{l}$; plasma or standard curve) were incubated with 5,000 cpm [125 I] Tyr ${ }^{12}$-Gastrin I (human, $2200 \mathrm{Ci} / \mathrm{mmol}$; Perkin Elmer Life and Analytical Sciences) and rabbit anti-gastrin Ab $(1.27 \mu \mathrm{g} / \mathrm{ml}$ final concentration; Dako Cytomation) in glass tubes coated with polyethylene glycol (2.5\%, 10,000 Da; Sigma-Aldrich). After incuba-

tion for $72 \mathrm{~h}$ at $4{ }^{\circ} \mathrm{C}$, gastrin was harvested after addition of $50 \mu \mathrm{l}$ newborn calf serum (Sigma-Aldrich) and $250 \mu 125 \%$ polyethylene glycol (8,000 Da; Sigma-Aldrich), followed by centrifugation at $500 \mathrm{~g}$ for $30 \mathrm{~min}$ at $4{ }^{\circ} \mathrm{C}$. Gastrin levels were calculated from the pellet radioactivity in comparison to a standard curve (2-500 pmol/l; human synthetic gastrin I diluted in heat-treated mouse serum; both from Sigma-Aldrich). The Ab recognizes nonsulphated and sulphated forms of gastrin-17 and -34 .

Statistics. Data are presented as mean \pm SEM. For protein and qRT-PCR analysis, changes in gene expression were analyzed using 2-tailed Student's $t$ test. A $P$ value less than 0.05 was considered significant.

\section{Acknowledgments}

We thank the following people for technical assistance: D. Baker and K. Miyake (Cell Imaging Core, Medical College of Georgia), R. Aaron and H. Yuen (Monoclonal Antibody Facility, University of Georgia, Athens, Georgia, USA), T. Stoming and J. Nechtman (Molecular Biology Core, Medical College of Georgia), P. Roon and R. Smith (Cell Biology and Anatomy Electron Microscopy Core, Medical College of Georgia), and Hai-Yen Qin (Medical College of Georgia). This study was supported by NIH grants RO1 DK56882 (to L.C. Samuelson), PO1 DK34933 (to L.C. Samuelson and J.L. Merchant), and RO1 DK31900 (to C.S. Chew) and by a University of Michigan Biomedical Research Council New Initiative Grant (to L.C. Samuelson).

Received for publication August 10, 2007, and accepted in revised form April 30, 2008.

Address correspondence to: Linda C. Samuelson, Department of Molecular and Integrative Physiology, University of Michigan, 2041 BSRB, 109 Zina Pitcher Place, Ann Arbor, Michigan 481092200, USA. Phone: (734) 764-9448; Fax: (734) 763-1166; E-mail: lcsam@umich.edu.

Catherine S. Chew and Linda C. Samuelson are co-senior authors.

1. Holtzman, D.A., Yang, S., and Drubin, D.G. 1993 Synthetic-lethal interactions identify two novel genes, SLA1 and SLA2, that control membrane cytoskeleton assembly in Saccharomyces cerevisiae. J. Cell Biol. 122:635-644.

2. Wesp, A., et al. 1997. End4p/Sla2p interacts with actin-associated proteins for endocytosis in Saccharomyces cerevisiae. Mol. Biol. Cell. 8:2291-2306.

3. Engqvist-Goldstein, A.E., et al. 2001. The actin-binding protein Hip1R associates with clathrin during early stages of endocytosis and promotes clathrin assembly in vitro. J. Cell Biol. 154:1209-1223.

4. Legendre-Guillemin, V., et al. 2002. HIP1 and HIP12 display differential binding to F-actin, AP2, and clathrin. Identification of a novel interaction with clathrin light chain. J. Biol. Chem. 277:19897-19904.

5. Carreno, S., Engqvist-Goldstein, A.E., Zhang, C.X., McDonald, K.L., and Drubin, D.G. 2004. Actin dynamics coupled to clathrin-coated vesicle formation at the trans-Golgi network. J. Cell Biol. 165:781-788.

6. Hyun, T.S., and Ross, T.S. 2004. HIP1: trafficking roles and regulation of tumorigenesis. Trends $\mathrm{Mol}$. Med. 10:194-199.

7. Legendre-Guillemin, V., Wasiak, S., Hussain, N.K., Angers, A., and McPherson, P.S. 2004. ENTH/ ANTH proteins and clathrin-mediated membrane budding. J. Cell Sci. 117:9-18.

8. Engqvist-Goldstein, A.E., et al. 2004. RNAi-mediated Hip1R silencing results in stable association between the endocytic machinery and the actin assembly machinery. Mol. Biol. Cell. 15:1666-1679.
9. Hyun, T.S., et al. 2004. HIP1 and HIP1r stabilize receptor tyrosine kinases and bind 3-phosphoinositides via epsin N-terminal homology domains. J. Biol. Chem. 279:14294-14306.

10. Hyun, T.S., et al. 2004. Hip1-related mutant mice grow and develop normally but have accelerated spinal abnormalities and dwarfism in the absence of HIP1. Mol. Cell. Biol. 24:4329-4340.

11. Bradley, S.V., et al. 2007. Degenerative phenotypes caused by the combined deficiency of murine HIP1 and HIP1r are rescued by human HIP1. Hum. Mol. Genet. 16:1279-1292.

12. Samuelson, L.C., and Hinkle, K.L. 2003. Insights into the regulation of gastric acid secretion through analysis of genetically engineered mice. Annu. Rev. Physiol. 65:383-400.

13. Okamoto, C.T., Karam, S.M., Jeng, Y.Y., Forte, J.G., and Goldenring, J.R. 1998. Identification of clathrin and clathrin adaptors on tubulovesicles of gastric acid secretory (oxyntic) cells. Am. J. Physiol. 274:C1017-C1029.

14. Jain, R.N., Brunkan, C.S., Chew, C.S., and Samuelson, L.C. 2006. Gene expression profiling of gastrin target genes in parietal cells. Physiol. Genomics. 24:124-132.

15. Hanby, A.M., et al. 1993. Spasmolytic polypeptide is a major antral peptide: distribution of the trefoil peptides human spasmolytic polypeptide and pS2 in the stomach. Gastroenterology. 105:1110-1116.

16. Jain, R.N., and Samuelson, L.C. 2006. Differentiation of the gastric mucosa. II. Role of gastrin in gastric epithelial cell proliferation and maturation. Am.
J. Physiol. Gastrointest. Liver Physiol. 291:G762-G765.

17. Friis-Hansen, L., et al. 1998. Impaired gastric acid secretion in gastrin-deficient mice. Am. J. Physiol. 274:G561-G568.

18. Engqvist-Goldstein, A.E., Kessels, M.M., Chopra, V.S., Hayden, M.R., and Drubin, D.G. 1999. An actin-binding protein of the Sla2/Huntingtin interacting protein 1 family is a novel component of clathrin-coated pits and vesicles. J. Cell Biol. 147:1503-1518.

19. Brett, T.J., Legendre-Guillemin, V., McPherson, P.S., and Fremont, D.H. 2006. Structural definition of the F-actin-binding THATCH domain from HIP1R. Nat. Struct. Mol. Biol. 13:121-130.

20. Okamoto, C.T., and Forte, J.G. 2001. Vesicular trafficking machinery, the actin cytoskeleton, and $\mathrm{H}^{+-\mathrm{K}+-A T P a s e}$ recycling in the gastric parietal cell. J. Physiol. 532:287-296.

21. Okamoto, C.T., et al. 2000. Clathrin in gastric acid secretory (parietal) cells: biochemical characterization and subcellular localization. Am. J. Physiol. Cell Physiol. 279:C833-C851.

22. Courtois-Coutry, N., et al. 1997. A tyrosine-based signal targets $\mathrm{H} / \mathrm{K}$-ATPase to a regulated compartment and is required for the cessation of gastric acid secretion. Cell. 90:501-510.

23. Nguyen, N.V., et al. 2004. Gastric parietal cell acid secretion in mice can be regulated independently of H/K ATPase endocytosis. Gastroenterology. 127:145-154

24. Cui, G., et al. 2006. Gastrin-induced apoptosis contributes to carcinogenesis in the stomach. Lab. 
Invest. 86:1037-1051.

25. Przemeck, S.M., et al. 2008. Hypergastrinemia increases gastric epithelial susceptibility to apoptosis. Regul. Pept. 146:147-156.

26. Rao, D.S., et al. 2001. Huntingtin interacting protein 1 Is a clathrin coat binding protein required for differentiation of late spermatogenic progenitors. Mol. Cell. Biol. 21:7796-7806.

27. Oravecz-Wilson, K.I., et al. 2004. Huntingtin Interacting Protein 1 mutations lead to abnormal hematopoiesis, spinal defects and cataracts. Hum. Mol. Genet. 13:851-867.

28. Rao, D.S., et al. 2002. Huntingtin-interacting protein 1 is overexpressed in prostate and colon cancer and is critical for cellular survival. J. Clin. Invest. 110:351-360

29. Rao, D.S., et al. 2003. Altered receptor trafficking in Huntingtin Interacting Protein 1-transformed cells. Cancer Cell. 3:471-482.

30. Hinkle, K.L., and Samuelson, L.C. 1999. Lessons from genetically engineered animal models. III. Lessons learned from gastrin gene deletion in mice. Am. J. Physiol. 277:G500-G505.

31. Walsh, J.H., Richardson, C.T., and Fordtran, J.S. 1975. $\mathrm{pH}$ dependence of acid secretion and gastrin release in normal and ulcer subjects. J. Clin. Invest. 55:462-468.

32. Wang, T.C., et al. 1996. Processing and proliferative effects of human progastrin in transgenic mice. J. Clin. Invest. 98:1918-1929.

33. Konda, Y., et al. 1999. Gastrin stimulates the growth of gastric pit with less-differentiated features. Am. J. Physiol. 277:G773-G784.

34. Franic, T.V., et al. 2001. Regulation of gastric epithelial cell development revealed in $\mathrm{H}(+) / \mathrm{K}(+)$-ATPase beta-subunit- and gastrin-deficient mice. Am.J. Physiol. Gastrointest. Liver Physiol. 281:G1502-G1511.

35. Fukushima, Y., et al. 2004. Unique roles of G protein-coupled histamine $\mathrm{H} 2$ and gastrin receptors in growth and differentiation of gastric mucosa. Eur.
J. Pharmacol. 502:243-252.

36. Ramsey, V.G., et al. 2007. The maturation of mucus-secreting gastric epithelial progenitors into digestive-enzyme secreting zymogenic cells requires Mist1. Development. 134:211-222.

37. Karam, S.M., and Leblond, C.P. 1993. Dynamics of epithelial cells in the corpus of the mouse stomach. III. Inward migration of neck cells followed by progressive transformation into zymogenic cells. Anat. Rec. 236:297-313

38. Nomura, S., et al. 2005. Alterations in gastric mucosal lineages induced by acute oxyntic atrophy in wild-type and gastrin-deficient mice. Am. J. Physiol. Gastrointest. Liver Physiol. 288:G362-G375.

39. Lopez-Diaz, L., et al. 2006. Parietal cell hyperstimulation and autoimmune gastritis in cholera toxin transgenic mice. Am. J. Physiol. Gastrointest. Liver Physiol. 290:G970-G979.

40. Judd, L.M., Gleeson, P.A., Toh, B.H., and van Driel, I.R. 1999. Autoimmune gastritis results in disruption of gastric epithelial cell development. Am. J Physiol. 277:G209-G218.

41. Nomura, S., et al. 2004. Spasmolytic polypeptide expressing metaplasia to preneoplasia in H. felisinfected mice. Gastroenterology. 127:582-594.

42. Schmidt, P.H., et al. 1999. Identification of a metaplastic cell lineage associated with human gastric adenocarcinoma. Lab. Invest. 79:639-646.

43. Wang, T.C., et al. 1998. Mice lacking secretory phospholipase A2 show altered apoptosis and differentiation with Helicobacter felis infection. Gastroenterology. 114:675-689.

44. Goldenring, J.R., and Nomura, S. 2006. Differentiation of the gastric mucosa III. Animal models of oxyntic atrophy and metaplasia. Am. J. Physiol. Gastrointest. Liver Physiol. 291:G999-G1004.

45. Kang, W., Rathinavelu, S., Samuelson, L.C., and Merchant, J.L. 2005. Interferon gamma induction of gastric mucous neck cell hypertrophy. Lab. Invest. 85:702-715.
46. Zavros, Y., Rieder, G., Ferguson, A., Samuelson, L.C., and Merchant, J.L. 2002. Hypergastrinemia in response to gastric inflammation suppresses somatostatin. Am. J. Physiol. Gastrointest. Liver Physiol. 282:G175-G183.

47. Zavros, Y., et al. 2003. Treatment of Helicobacter gastritis with IL-4 requires somatostatin. Proc. Natl. Acad. Sci. U. S. A. 100:12944-12949.

48. Li, Q., Karam, S.M., and Gordon, J.I. 1995. Simian virus $40 \mathrm{~T}$ antigen-induced amplification of pre-parietal cells in transgenic mice. Effects on other gastric epithelial cell lineages and evidence for a p53-independent apoptotic mechanism that operates in a committed progenitor. J. Biol. Chem. 270:15777-15788.

49. Nozaki, K., et al. 2008. A molecular signature of gastric metaplasia arising in response to acute parietal cell loss. Gastroenterology. 134:511-522.

50. Chew, C.S., Okamoto, C.T., Chen, X., and Qin, H.Y. 2005. IQGAPs are differentially expressed and regulated in polarized gastric epithelial cells. Am.J. Physiol. Gastrointest. Liver Physiol. 288:G376-G387.

51. Chew, C.S., et al. 2002. Lasp-1 binds to non-muscle $\mathrm{F}$-actin in vitro and is localized within multiple sites of dynamic actin assembly in vivo. J. Cell Sci. 115:4787-4799.

52. Chew, C.S., Parente, J.A., Jr., Chen, X., Chaponnier, C., and Cameron, R.S. 2000. The LIM and SH3 domain-containing protein, lasp-1, may link the cAMP signaling pathway with dynamic membrane restructuring activities in ion transporting epithelia. J. Cell Sci. 113:2035-2045.

53. Chew, C.S. 1990. cAMP technologies, functional correlates in gastric parietal cells. Methods Enzymol. 191:640-661.

54. Hinkle, K.L., Bane, G.C., Jazayeri, A., and Samuelson, L.C. 2003. Enhanced calcium signaling and acid secretion in parietal cells isolated from gastrin-deficient mice. Am. J. Physiol. Gastrointest. Liver Physiol. 284:G145-G153. 